\title{
EVALUASI SENSOR FIT0348 SEBAGAI ALAT UKUR POTENTIAL OF HYDROGEN (PH) LARUTAN
}

\section{EVALUATION OF SENSOR FIT0348 AS MEASURING INSTRUMENT OF POTENTIAL OF HYDROGEN (PH) SOLUTION}

\author{
Banu Sudewa ${ }^{1}$, Febrian Hadiatna ${ }^{2}$ \\ ${ }^{1,2}$ Jurusan Teknik Elektro, Fakultas Teknologi Industri, Institut Teknologi Nasional Bandung \\ 1id.sudewa@hotmail.com, ${ }^{2}$ febrian_hadiatna@yahoo.com
}

\begin{abstract}
Abstrak
Pada penelitian ini dilakukan Evaluasi pada sensor pH FIT0348 sebagai alat ukur pH berbasis mikrokontroler. Evaluasi ini dilakukan untuk mengetahui seberapa besar tingkat akurasi, ketidakpastian dalam kalibrasi dan kenaikan $\mathrm{pH}$ air. Evaluasi ini merupakan tahapan untuk menguji kualitas sensor yang nantinya akan diintegrasikan sebagai alat pemantau dan pengendali $\mathrm{pH}$ pertanian pada pertanian modern. Perancangan dan Implementasi prototype sistem pemantauan $\mathrm{pH}$ terdiri dari sensor $\mathrm{pH}$ FIT0348, mikrokontroler ATmega16A, rangkaian amplifier, personal computer. Pengujian dilakukan dengan cara melakukan kalibrasi, dan pemantauan derajat keasaman larutan selama 20 jam dengan interval pengambilan data 1 jam. Larutan yang menjadi objek pengujian adalah air mineral sebanyak $500 \mathrm{~mL}$. Dalam proses pengujian digunakan alat ukur PH/EC-9853 dan kertas lakmus sebagai pembanding hasil pengukuran $\mathrm{pH}$ dari sensor $\mathrm{pH}$ FIT0348. Hasil penelitian menunjukkan bahwa tingkat akurasi dari sensor pH FIT0348 adalah $\pm 97,2 \%$ jika dibandingkan dengan alat ukur PH/EC-9853, pH larutan mengalami fluktuasi sebesar 0,01 hingga 0,02 setiap jamnya, ketidakpastian hasil pengukuran sensor $\mathrm{pH}$ terbesar adalah $\pm 5.278 \times 10^{-05}$, sehingga memungkinkan untuk digunakan pada pengembangan sistem pemantau dan pengandali nutrisi tanaman.
\end{abstract}

Kata kunci : sensor pH FIT0348, ATmega16A, alat ukur pH, evaluasi sensor, tingkat akurasi, ketidakpastian, fluktuasi pH

\begin{abstract}
The accuracy of pH sensor FIT0348 was evaluated for microcontroller based for monitoring $\mathrm{pH}$. Evaluation was performed in order to know how accuracy sensor $\mathrm{pH}$, uncertanty value in calibration, and $\mathrm{pH}$ fluctuations. The purpose of this evaluation is to get the best result of sensor before be used for monitoring and controlling $\mathrm{pH}$ for hydroponic. The design and implementation of system consist of pH sensor FIT0348, microcontroller ATmega16A, amplifier circuit, personal computer. The test will be calibration process of $\mathrm{pH}$, and 19 hours of monitoring $\mathrm{pH}$ of water 500 $\mathrm{mL}$. Monitored data will be received every one hour. Both of system need to calibrate in order to get the right value of $\mathrm{pH}$. Also, lakmus paper and $\mathrm{PH} / \mathrm{EC}-9853$ used in this study in order to know which range $\mathrm{pH}$ solution is. Result are sensor FIT0348 has accuracy about $\pm 97,2 \%$ compared to $\mathrm{pH} / \mathrm{EC}-9853, \mathrm{pH}$ water fluctuated every 1 hour about 0,01 to 0,02 and uncertainty value of sensor $\mathrm{pH}$ was about $\pm 5,278 \times 10^{-05}$. Based on the result this sensor can be used for monitoring and controlling system nutrition plant.
\end{abstract}

Keywords: pH sensor FIT0348, ATmega16A, accuracy of pH sensor FIT0348, sensor's evaluation, fluctuation of $\mathrm{pH}$, uncertainty value 


\section{PENDAHULUAN}

Hidroponik merupakan salah satu metoda bercocok tanam dengan menggunakan air yang mengandung nutrisi dan oksigen terlarut sebagai media tanamnya [1]. Pada metoda bercocok tanam ini, nutrisi dan oksigen terlarut memiliki peranan penting terhadap pertumbuhan tanaman. Pada nutrisi tanaman terdiri dari beberapa kandungan penting didalamnya, diantaranya nitrogen, kalium, fosfor, kalsium, magnesium, boron, besi, chlore, cobalt, potential of Hydrogen, dsb. Berkembangnya teknologi dari alat ukur saat ini, mengakibatkan beberapa kandungan nutrisi tanaman tersebut memungkinkan untuk dilakukan proses pengukuran sehingga kandungan nutrisi dapat terjaga. Salah satu dari kandungan nutrisi yang saat ini telah dapat diukur adalah kandungan $\mathrm{pH}$ (potential of hydrogen). Pertumbuhan tanaman akan subur jika nilai $\mathrm{pH}$ nutrisinya berada dikisaran 6 hingga 7,6.

Derajat keasaman atau $\mathrm{pH}$ adalah konsentrasi ion hidrogen yang sangat kecil [2]. $\mathrm{pH}$ didefinisikan sebagai logaritma basis -10 dari konsentrasi ion hidrogen [2]. Kandungan pH, dibutuhkan oleh tanaman dalam nilai tertentu untuk memperoleh pertumbuhan yang optimal. Kandungan $\mathrm{pH}$ yang berlebih atau kurang, mengakibatkan terhambatnya pertumbuhan tanaman. Derajat keasaman memiliki perubahan nilai dalam kurun waktu tertentu. $\mathrm{pH}$ akan berubah tidak menentu bergantung kepada faktor-faktor yang mempengaruhinya. Faktor tersebut diantaranya suhu, proses dekomposisi bahan organik, fotosintesi ataupun adanya unsur lain yang terendam kedalam air [3].

$\mathrm{pH}$ meter adalah alat ukur yang dapat memberikan informasi mengenai derajat keasaman suatu larutan. Alat ukur ini menggunakan sebuah probe yang terbuat dari silinder kaca nonkonduktor yang berfungsi sebagai sensornya [4]. Dengan memanfaatkan senyawa $\mathrm{HCl}$ yang merendam kawat elektroda, alat ini mampu mengukur derajat keasaman yang terkandung dalam air [4]. Namun, terdapat beberapa permasalahan yang dialami saat proses penggunaan alat ukur tersebut, diantaranya proses kalibrasi, lifetime alat ukur, tingkat akurasi hasil pengukuran dan sebagainya.

Pemanfaatan sensor $\mathrm{pH}$ dibandingkan dengan alat ukur $\mathrm{pH}$ portable yaitu dapat digunakan pada pengembangan sistem pemantau dan pengendali nutrisi tanaman. Derajat keasaman pada nutrisi tanaman dapat diatur nilainya dan dijaga kestabilannya, dengan mengintegrasikan sensor ini di sistem tersebut. Saat ini terdapat beberapa perangkat sensor $\mathrm{pH}$ yang dikembangkan oleh beberapa produsen, salah satunya adalah sensor FIT0348. Pada penelitian ini, dilakukan proses evaluasi terhadap perangkat sensor FIT0348, untuk mengetahui karakteristik dari sensor tersebut. Hal ini bermanfaat untuk pemilihan perangkat sensor yang akan digunakan untuk pengembangan sistem pemantau dan pengendali nutrisi tanaman. Penelitian ini tidak membahas mengenai waktu penentuan kalibrasi ulang. Metoda pengujian yang digunakan dalam penelitian ini adalah dengan membandingkan hasil pengukuran sensor FIT0348 sebagai alat ukur pH dengan alat ukur PH/EC9853 dan kertas lakmus.

\section{PERANCANGAN DAN IMPLEMENTASI SISTEM}

\subsection{Perancangan Sistem}

Pada penelitian ini, sistem yang dirancang digambarkan dalam sebuah blok diagram yang terdapat pada Gambar 1. 


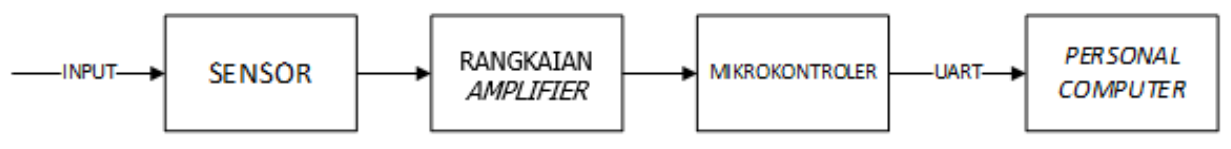

Gambar 1. Blok diagram sistem

Berdasarkan Gambar 1, tampak bahwa nilai $\mathrm{pH}$ pada larutan akan dideteksi oleh perangkat sensor $\mathrm{pH}$. Perangkat tersebut mengkonversi nilai $\mathrm{pH}$ menjadi bentuk sinyal tegangan analog yang relatif kecil nilainya, sehingga dilakukan proses penguatan dengan menambahkan rangkaian amplifier, sehingga mampu diproses oleh mikrokontroler (MCU). Mikrokontroler akan mengolah data tersebut menjadi sebuah informasi hasil pengukuran yang ditampilkan pada perangkat personal computer melalui komunikasi UART.

Pada bagian perangkat lunak dirancang sebuah algoritma yang berfungsi untuk melakukan proses akuisisi data, sehingga dihasilkan informasi hasil pengukuran yang lebih akurat dan presisi. Berikut ini Gambar 2, adalah flowchart dari perangkat lunak yang dirancang.

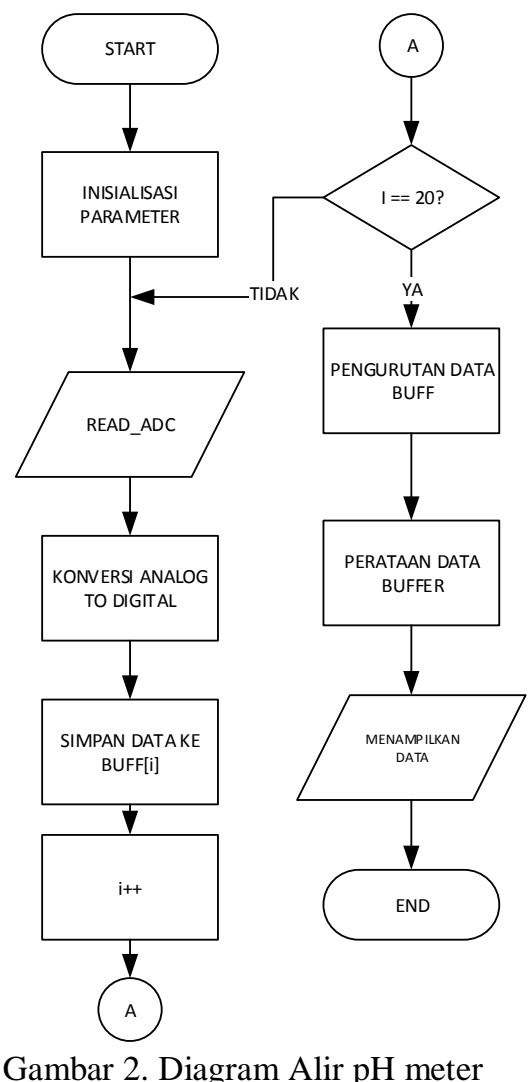

Berdasarkan Gambar 2, tampak bahwa program yang dirancang dimulai dari MCU melakukan proses inisialisasi seluruh parameter yang akan digunakan. Setelah proses inisialisasi selesai, selanjutnya MCU melakukan proses deteksi data dari sensor, dengan cara mengaktifkan fitur ADC. Data yang diperoleh dari ADC akan disimpan pada variabel array buff[i]. Proses tersebut dilakukan secara terus-menerus dengan mengisi data pada variabel buff[1] sampai dengan variabel buff[20]. Setelah data hasil pengukuran disimpan pada 20 buah variabel buff, selanjutnya seluruh data tersebut akan diurutkan dari nilai terkecil hingga terbesar. Data yang telah terurut selanjutnya mengalami perataan data dengan menggunakan data ke 6 hingga 15 yang telah diurutkan. Hasil olah data tersebut selanjutnya akan ditampilkan pada PC, sebagai data hasil pengukuran $\mathrm{pH}$. 


\subsection{Implementasi Sistem}

Berdasarkan hasil perancangan, maka sistem tersebut direalisasikan dengan menggunakan beberapa perangkat keras, diantaranya FIT0348 sebagai sensor pH, dan ATmega16A sebagai MCU. Sensor FIT0348 memiliki output data yang relatif kecil, sehingga tidak memungkinkan dilakukan proses pengolahan secara langsung oleh perangkat MCU. Oleh karena itu, diperlukan sebuah perangkat driver yang berfungsi sebagai penguat sinyal. Berikut Gambar 3 yang menunjukan rangkaian driver yang digunakan sebagai penguat sensor FIT0348.

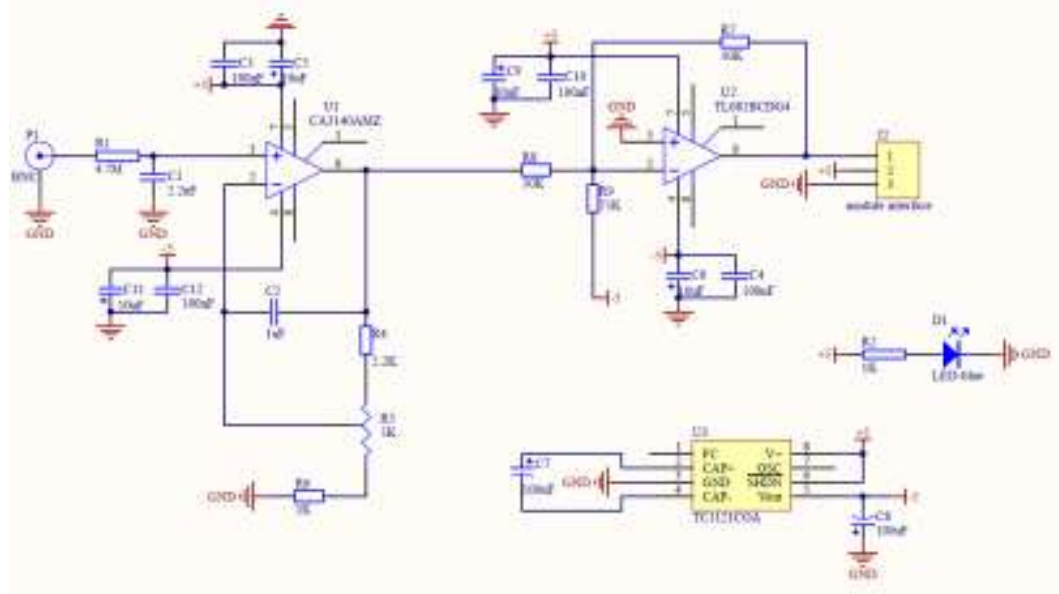

Gambar 3 Rangkaian driver $\mathrm{pH}$ meter [5]

Sensor FIT0348 merupakan sensor pH yang dikhususkan untuk penggunaan industri, dimana pemakaian sensor tersebut dapat melebihi pemakaian 24 jam, berbeda dengan sensor lainnya yang pada umumnya tidak dapat digunakan secara terus-menerus di dalam larutan. Sensor ini memiliki kepresisian sebesar $0,02 \mathrm{pH}$, dengan drift sebesar $0,02 \mathrm{pH}$ per 24 jam, respon waktu selama 10 detik untuk mendapatkan nilai yang stabil, memiliki slope diatas $95 \%$, serta range pengukuran mulai dari nilai 0 hingga $14 \mathrm{pH}$, dan electrode's epuipotential point 7 $\pm 0,5 \mathrm{pH}$.

Berdasarkan Gambar 3, Rangkaian driver sensor pH FIT0348 terdiri dari rangkaian amplifier CA3410AMZ dan TL081BCD64. Data keluaran sensor menjadi data masukan untuk rangkaian amplifier CA3410AMZ. Pada rangkaian amplifier tersebut, data akan diolah dengan penguatan noninverting. Data keluaran dari proses penguatan tersebut masih belum dapat diolah oleh MCU karena masih relatif kecil, sehingga diolah kembali oleh rangkaian amplifier TL081BCD64 non-inverting. Pada rangkaian driver tersebut terdapat IC TC1121COA yang berfungsi untuk menghasilkan tegangan negatif yang digunakan sebagai catu daya pada tegangan negatif op-amp.

ATmega16A digunakan sebagai MCU pada sistem ini. Mikrokontroler tersebut memiliki spesifikasi 40-pin PDIP dengan 32 pin I/O yang dapat diprogram. Tegangan kerja mikrokontroler ini sekitar 2,7 hingga 5,5 Volt DC. Kapasitas memory yang dimiliki adalah 16 Kbyte yang merupakan InSystem Self-Programmable Flash program memory, 512 EEPROM, 1 Kbyte Internal SRAM. Memiliki 4 PWM channel, 8 channel 10-bit ADC. Spesifikasi tersebut cocok untuk digunakan dalam sistem ini. Mikrokontroller ini memiliki peranan untuk mengolah data input menjadi data output yang nantinya dikirim ke PC melalui komunikasi UART.

\section{METODA PENGUJIAN}

Metoda yang digunakan dalam penelitian ini adalah dengan melakukan perbandingan antara sensor FIT0348 dengan alat ukur PH/EC-9853 dan kertas lakmus. Alat yang digunakan pada pengujian tampak pada gambar 4. 


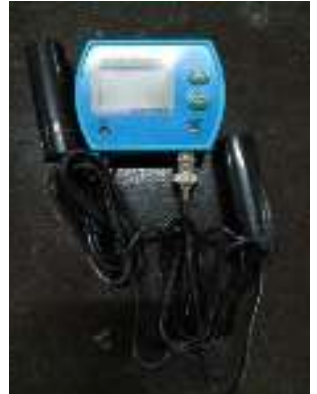

(a)

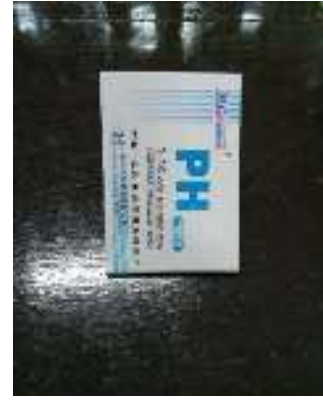

(b)

Gambar 4 (a) PH/EC-9853 (b) Kertas Lakmus

Metoda yang digunakan dalam pengujian ini dilakukan dengan 2 tahap yaitu kalibrasi dan pengambilan data secara berkala. Pada tahap pertama dilakukan proses kalibrasi yang bertujuan untuk melakukan validasi pengkuran agar sesuai dengan standar pengukuran $\mathrm{pH}$ yang sifatnya international [6]. Proses kalibrasi menggunakan calibration powder sebagai pembanding nilai standar. Calibration powder tersebut harus dilarutkan pada air sebanyak $100 \mathrm{~mL}$. Nilai kalibrasi terdiri dari 3 variasi nilai yang berbeda, yaitu 4,00;6,86;9,18. Kalibrasi dilakukan dengan cara menyamakan nilai yang tertera pada display dengan kemasan serbuk. Proses pengaturan nilai dilakukan dengan cara mengatur nilai resistor variabel yang terdapat pada rangkaian driver. Berikut Gambar 5 yang menunjukan proses kalibrasi.

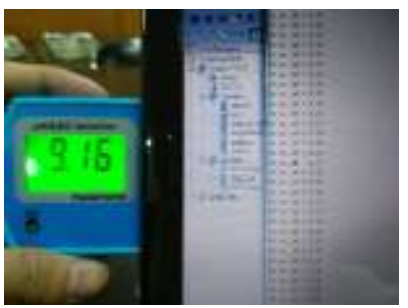

(a)

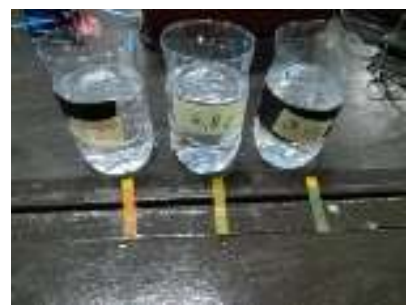

(b)

Gambar 5 (a) Proses kalibrasi alat (b) Air yang sudah terkalibrasi

Setelah proses kalibrasi selesai dilakukan, pada tahap berikutnya dilakukan proses pengambilan data secara berkala. Pada tahap kedua dilakukan proses pengambilan data pada objek larutan selama 20 jam dengan interval pengambilan data setiap 1 jam. Hal ini dilakukan dengan tujuan untuk mendapatkan akurasi dari sensor $\mathrm{pH}$ sebagai alat ukur. Proses pengambilan data ini memanfaatkan ip-camera untuk melakukan capture data selama 1 jam sekali dengan kendali melalui smartphone. Proses pengambilan data melalui kamera tampak seperti gambar 6.

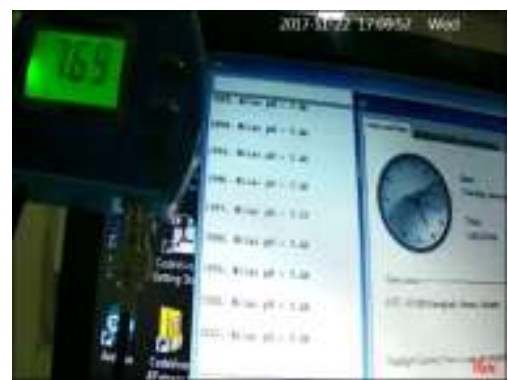

Gambar 6 pengambilan data menggunakan kamera 
Pengambilan data yang ditunjukan (gambar 6) diakses melalui internet dengan menggunakan app V380. Aplikasi tersebut memungkinkan pengguna untuk mengakses kamera melalui app tersebut selama kedua device terhubung dengan internet dan memenuhi persyaratan lainnya. Dilakukan juga pengukuran menggunakan kertas lakmus sebagai pembanding data ke 3 . Pengukuran dilakukan secara manual. Salah satu hasil yang didapatkan dalam pengujian menggunakan kertas lakmus ditunjukan olah Gambar 7.

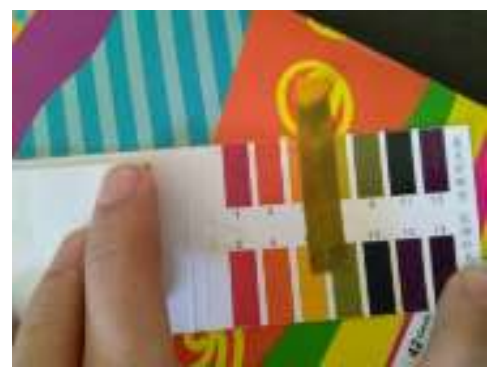

Gambar 7 Hasil pengukuran menggunakan kertas lakmus

\section{DATA PENGAMATAN}

Pada sub bab ini akan dipaparkan hasil yang didapatkan setelah pengujian. Hasil kalibrasi yang dilakukan ditunjukan pada Tabel 1 .

Tabel 1 Hasil kalibrasi pH meter

\begin{tabular}{|c|c|c|c|c|c|c|}
\hline $\begin{array}{c}\text { pH } \\
\text { Serbuk }\end{array}$ & $\begin{array}{c}\text { Pengujian } \\
\text { ke- }(\mathbf{N})\end{array}$ & $\begin{array}{c}\text { FIT0348 } \\
\left(\left(\boldsymbol{x}_{\boldsymbol{i}}\right)\right.\end{array}$ & $\left(x_{i}-\bar{x}\right)^{2}$ & $\mathbf{s}$ & $\Delta \boldsymbol{x}$ & $\Delta \mathbf{p H}$ \\
\hline \multirow{10}{*}{4,00} & 1 & 4 & $8.1 \mathrm{E}-05$ & \multirow{10}{*}{0.002333333} & \multirow{10}{*}{0.005278} & \multirow{10}{*}{$5.278 \mathrm{E}-05$} \\
\hline & 2 & 4 & $8.1 \mathrm{E}-05$ & & & \\
\hline & 3 & 4 & $8.1 \mathrm{E}-05$ & & & \\
\hline & 4 & 4.01 & $1 \mathrm{E}-06$ & & & \\
\hline & 5 & 4.01 & $1 \mathrm{E}-06$ & & & \\
\hline & 6 & 4.02 & 0.0001210 & & & \\
\hline & 7 & 4.01 & $1 \mathrm{E}-06$ & & & \\
\hline & 8 & 4.01 & $1 \mathrm{E}-06$ & & & \\
\hline & 9 & 4.01 & $1 \mathrm{E}-06$ & & & \\
\hline & 10 & 4.02 & 0.000121 & & & \\
\hline \multirow{10}{*}{6,86} & 1 & 6.84 & 9E-06 & \multirow{10}{*}{0.001527525} & \multirow{10}{*}{0.00345526} & \multirow{10}{*}{$3.4553 \mathrm{E}-05$} \\
\hline & 2 & 6.84 & 9E-06 & & & \\
\hline & 3 & 6.84 & 9E-06 & & & \\
\hline & 4 & 6.85 & $4.9 \mathrm{E}-05$ & & & \\
\hline & 5 & 6.84 & 9E-06 & & & \\
\hline & 6 & 6.84 & 9E-06 & & & \\
\hline & 7 & 6.85 & $4.9 \mathrm{E}-05$ & & & \\
\hline & 8 & 6.84 & 9E-06 & & & \\
\hline & 9 & 6.85 & $4.9 \mathrm{E}-05$ & & & \\
\hline & 10 & 6.84 & 9E-06 & & & \\
\hline \multirow{2}{*}{9,18} & 1 & 9.16 & $3.15544 \mathrm{E}-30$ & \multirow{2}{*}{$5.92119 \mathrm{E}-16$} & \multirow{2}{*}{$1.3394 \mathrm{E}-15$} & \multirow{2}{*}{$1.339 \mathrm{E}-17$} \\
\hline & 2 & 9.16 & $3.15544 \mathrm{E}-30$ & & & \\
\hline
\end{tabular}




\begin{tabular}{|l|l|r|r|}
\hline 3 & 9.16 & $3.15544 \mathrm{E}-30$ \\
\hline 4 & 9.16 & $3.15544 \mathrm{E}-30$ \\
\hline 5 & 9.16 & $3.15544 \mathrm{E}-30$ \\
\hline 6 & 9.16 & $3.15544 \mathrm{E}-30$ \\
\hline 7 & 9.16 & $3.15544 \mathrm{E}-30$ \\
\hline 8 & 9.16 & $3.15544 \mathrm{E}-30$ \\
\hline 9 & 9.16 & $3.15544 \mathrm{E}-30$ \\
\hline 10 & 9.16 & $3.15544 \mathrm{E}-30$ &
\end{tabular}

Berdasarkan tabel 1, $\mathrm{pH}$ yang didapatkan mengalami perubahan dalam pengukuran kalibrasi. Perubahan tersebut merupakan hal yang wajar dari sebuah alat ukur karena setiap alat ukur memiliki error atau nilai ketidakpastian. Dengan memanfaatkan variansi nilai yang didapat, nilai $\mathrm{s}$ (standar deviasi) memungkinkan untuk dilakukan perhitungan dengan menggunakan rumus (1).

$$
\mathrm{S}=\sqrt{\frac{\sum\left(\boldsymbol{x}_{\boldsymbol{i}}-\overline{\boldsymbol{x}}\right)^{\mathbf{2}}}{N(\mathrm{~N}-1)}}
$$

Dengan menggunakan teori CF (confidence level), probabilitas cakupan yang diperoleh dengan pendekatan pertama digunakan untuk mengubah nilai interval ketidakpastian [6]. Nilai level kepercayaan (confidence level) yang digunakan adalah 95\%, penggunaan nilai dalam perhitungan digunakan tabel confidence level berdasarkan literatur [6]. Nilai $\Delta \boldsymbol{x}$ digunakan untuk mendapatkan nilai ketidakpastian total dengan menggunakan rumus (2)

$$
\Delta \mathrm{pH}=\sqrt{\Delta \boldsymbol{x}^{2} x 0.1^{2}}
$$

Nilai 0.1 diperoleh dari nilai ketidakpastian serbuk kalibrasi yang tercatat dalam kemasan serbuk. Berdasarkan hasil perhitungan ketidakpastian, dapat ditarik kesimpulan dalam setiap pengukuran mengalami kemungkinan nilai yang berada diantara $\Delta \mathrm{Ph}$ yang diperoleh.

Sedangkan hasil pengukuran yang telah dilakukan selama 20 jam ditunjukan pada Tabel 2.

Tabel 2 Hasil pengukuran pH selama 20 jam

\begin{tabular}{|r|c|c|c|c|}
\hline $\mathbf{N}$ & Waktu & $\begin{array}{c}\mathbf{P H} / \mathbf{E C} \\
\mathbf{9 8 5 3}\left(\mathbf{P}_{\mathbf{i}}\right)\end{array}$ & $\begin{array}{c}\text { Kertas } \\
\text { Lakmus }\end{array}$ & $\begin{array}{c}\text { FIT0348 } \\
\left(\mathbf{J}_{\mathbf{i}}\right)\end{array}$ \\
\hline 1 & 06.00 & 7,64 & $7<\mathrm{pH}<8$ & 7,48 \\
\hline 2 & 07.00 & 7,65 & $7<\mathrm{pH}<8$ & 7,5 \\
\hline 3 & 08.00 & 7,66 & $7<\mathrm{pH}<8$ & 7,51 \\
\hline 4 & 09.00 & 7,66 & $7<\mathrm{pH}<8$ & 7,51 \\
\hline 5 & 10.00 & 7,66 & $7<\mathrm{pH}<8$ & 7,53 \\
\hline 6 & 11.00 & 7,65 & $7<\mathrm{pH}<8$ & 7,53 \\
\hline 7 & 12.00 & 7,65 & $7<\mathrm{pH}<8$ & 7,53 \\
\hline 8 & 13.00 & 7,68 & $7<\mathrm{pH}<8$ & 7,53 \\
\hline 9 & 14.00 & 7,68 & $7<\mathrm{pH}<8$ & 7,54 \\
\hline 10 & 15.00 & 7,68 & $7<\mathrm{pH}<8$ & 7,56 \\
\hline 11 & 16.00 & 7,69 & $7<\mathrm{pH}<8$ & 7,57 \\
\hline 12 & 17.00 & 7,69 & $7<\mathrm{pH}<8$ & 7,56 \\
\hline 13 & 18.00 & 7,7 & $7<\mathrm{pH}<8$ & 7,53 \\
\hline 14 & 19.00 & 7,7 & $7<\mathrm{pH}<8$ & 7,53 \\
\hline 15 & 20.00 & 7,72 & $7<\mathrm{pH}<8$ & 7,53 \\
\hline
\end{tabular}




\begin{tabular}{|c|c|c|c|c|}
\hline 16 & 21.00 & 7,72 & $7<\mathrm{pH}<8$ & 7,53 \\
\hline 17 & 22.00 & 7,73 & $7<\mathrm{pH}<8$ & 7,53 \\
\hline 18 & 23.00 & 7,73 & $7<\mathrm{pH}<8$ & 7,54 \\
\hline 19 & 00.00 & 7,74 & $7<\mathrm{pH}<8$ & 7,55 \\
\hline 20 & 01.00 & 7,75 & $7<\mathrm{pH}<8$ & 7,54 \\
\hline
\end{tabular}

Berdasarkan Tabel 2, terjadi peningkatan nilai $\mathrm{pH}$ setiap jamnya, hal ini terjadi dikarenakan faktorfaktor yang membuat perubahan nilai $\mathrm{pH}$ air [4]. Terdapat selisih perbedaan antara alat ukur PH/EC-9853 dan alat ukur yang dibangun. Perbedaan tersebut berkisar antara 0,2 - 0,3. Perbedaan nilai tersebut dapat diatasi dengan memanfaatkan offset dalam program yang dikembangkan, di sisi lain nilai yang terukur terbilang benar jika dibandingkan dengan kertas lakmus karena nilai yang terukur masih berada diantara 7 dan 8 . Kenaikan $\mathrm{pH}$ yang dialami larutan perjamnya berkisar antara 0,01 hingga 0,02. Berdasarkan data selisih terbesar antara sensor pH FIT0348 dengan alat ukur PH/EC-9853, digunakan untuk mencari tingkat akurasi sensor pH FIT0348 terhadap alat ukur PH/EC-9853 dengan menggunakan rumus (3).

$$
\text { Akurasi }=\frac{P_{i}}{J_{i}} \times 100 \%=\frac{7.54}{7.75} \times 100 \%=97.2 \%
$$

Data pengukuran yang telah dikonversi ke bentuk grafik ditunjukan oleh Gambar 8.

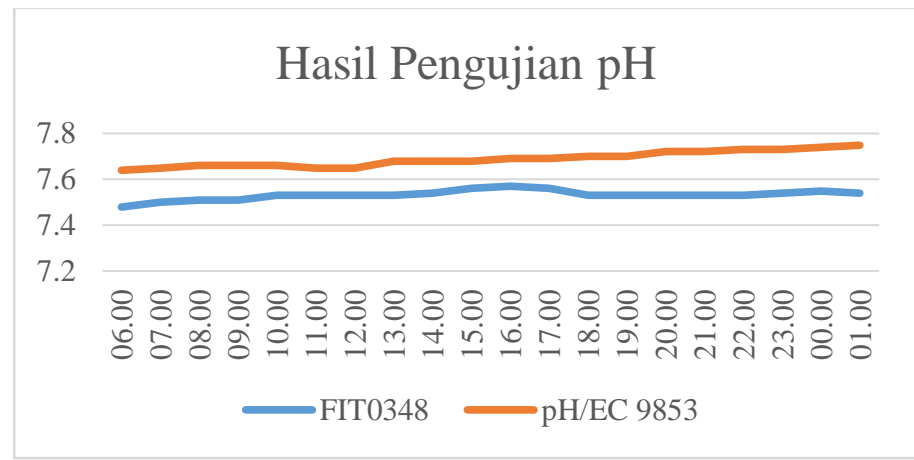

Gambar 8 Grafik pengujian $\mathrm{pH}$

Berdasarkan grafik yang ditunjukan oleh Gambar 8, pH yang terukur mengalami fluktuasi selama pengujian. Perubahan tersebut terjadi karena faktor lingkungan, dekomposisi, suhu, unsur lainnya yang tercampur ke dalam air [3].

\section{KESIMPULAN}

Berdasarkan pengujian dan pengambilan data dari sistem pemantau $\mathrm{pH}$ dan EC yang telah dibuat, dapat disimpulkan sebagai berikut:

a. Akurasi sensor $\mathrm{pH}$ meter yang dibuat dibandingkan dengan $\mathrm{pH} / \mathrm{EC} 9853$ dan kertas lakmus memiliki tingkat keakurasian sebesar $\pm 97.2 \%$.

b. Dalam kurun waktu 1 jam sekali nilai $\mathrm{pH}$ air mengalami perubahan nilai sebesar 0,01 hingga 0,02 , sehingga pemantauan $\mathrm{pH}$ terbukti memang harus dilakukan pada sistem penanaman hidroponik.

c. Nilai ketidakpastian terbesar sensor pH FIT0348 adalah $\pm 5.278 \times 10^{-05}$.

d. Perbedaan nilai sebesar 0,2 hingga 0,3 dapat diatasi dengan memanfaatkan offset pada program. 


\section{DAFTAR PUSTAKA}

[1] Roidah dan I. Syamsu, "Pemanfaatan Lahan Dengan Menggunakan Hidroponik," Jurnal Universitas Tulungagung BONOWORO Vol.1, 2014.

[2] M. A. I. Shahrulakram , J. Johari, "Water Storage Monitoring System with $\mathrm{pH}$ Sensor for Pharmaceutical Plants," IEEE 6th International Conference on System Engineering and Technology (ICSET), 3-4 Oktober 2016.

[3] Taufiqullah, "Faktor Yang Menentukan Nilai pH Air," 11 September 2017. online. Available: www.tneutron.net/blog/faktor-yang-menentukan-nilai-ph-air/. Diakses : 29 Desember 2017].

[4] ONNY, "Prinsip Kerja pH Meter," online. Available: artikel-teknologi.com/prinsip-kerja-phmeter/. Diakses : Desember 2017

[5] “industrial pH electrode(SKU:FIT0348)," online. Available: www.dfrobot.com/wiki/index.php/Industrial_pH_electrode(SKU:FIT0348). Diakses : Desember 2017

[6] S. Anwari, "Kalibrasi Sistem Pengukuran," Prosiding Seminar Nasional Energi Telekomunikasi dan Otomasi (SNETO), pp. 53 - 1-7, 2017. 